OPEN ACCESS

Edited by:

Jianxin Jiang,

Wuhan University, China

Reviewed by:

Ganshu Xia,

Anyang Tumor Hospital, China

Weihong Duan,

Rocket Army General Hospital, China

${ }^{*}$ Correspondence:

Renyi Qin

ryqin@tjh.tjmu.edu.cn

Tingmei Wang

dwtm198935@126.com

Specialty section:

This article was submitted to Gastrointestinal Cancers: Hepato

Pancreatic Biliary Cancers,

a section of the journal

Frontiers in Oncology

Received: 25 August 2021

Accepted: 14 October 2021

Published: 05 November 2021

Citation:

Dang C, Wang M, Wang T and Qin R (2021) Intraoperative $\mathrm{pH}$ Is a Reliable

Prognostic Factor for Patients With

Periampullary Carcinoma Undergoing

Pancreaticoduodenectomy.

Front. Oncol. 11:764572.

doi: 10.3389/fonc.2021.764572

\section{Intraoperative pH Is a Reliable Prognostic Factor for Patients With Periampullary Carcinoma Undergoing Pancreaticoduodenectomy}

\author{
Chao Dang ${ }^{1}$, Min Wang ${ }^{1}$, Tingmei Wang ${ }^{2 *}$ and Renyi Qin ${ }^{1 *}$ \\ ${ }^{1}$ Department of Pancreatic-Biliary Surgery, Affiliated Tongji Hospital, Tongji Medical College, Huazhong University of Science \\ and Technology, Wuhan, China, ${ }^{2}$ Department of Dermatology, Affiliated Tongji Hospital, Tongji Medical College, Huazhong \\ University of Science and Technology, Wuhan, China
}

A reliable prognostic factor for periampullary carcinoma is critical to improve surgical outcomes. Intraoperative acidosis reflects the incidence of intraoperative adverse events and impact the prognosis. In this study, 612 patients with periampullary carcinoma who underwent pancreaticoduodenectomy (PD) were divided into high- and low-pH groups according to the cut-off value of receiver operating characteristic curve (7.34). Through statistical analysis of the difference between the high- and low-pH group, it was found that the low-pH group had worse short-term prognosis than the high $\mathrm{pH}$ group, and intraoperative $\mathrm{pH}$ was an independent prognostic factor for patients with periampullary carcinoma undergoing PD. In addition, patients who underwent laparoscopic pancreaticoduodenectomy had a more alkaline $\mathrm{pH}$ after surgery. This is of great help for early judgment of short-term and even long-term prognosis of patients with pancreatic cancer after surgery, and can even guide clinicians to improve prognosis by early adjustment of $\mathrm{pH}$ value.

Keywords: pancreaticoduodenectomy, pancreatic cancer, $\mathrm{pH}$, prognostic factor, weakly alkaline

\section{INTRODUCTION}

Periampullary adenocarcinoma, which may originate in the pancreas, distal common bile duct, duodenum, or ampulla, is a common malignancy with an increasing incidence in recent years (1). Pancreaticoduodenectomy (PD) is a major abdominal procedure for the treatment of periampullary adenocarcinoma, but it has a high inpatient mortality rate $(2,3)$. Postoperative complications are potential causes of death after PD $(4,5)$. Early prediction of postoperative complications and reduction of short-term mortality are important for improving the prognosis of periampullary carcinoma.

A low serum $\mathrm{pH}$ is associated with increased complications and mortality after major surgery $(6,7)$. In fact, intraoperative acidosis reflects the incidence of intraoperative adverse events, and deficient tissue perfusion is an important factor affecting healing. A prolonged duration of 
intraoperative hypotension, excessive blood loss, excessive blood transfusion, hypothermia, a long operation time, an improper operative technique, inadequate drug administration, excessive fluid administration, or the occurrence of clinically negligible adverse events can lead to intraoperative metabolic acidosis, which reflects inadequate tissue perfusion (8). PD is associated with a long operation time, large amount of blood loss, and risk of hypothermia, resulting in acidosis. However, few studies have addressed the effect of $\mathrm{pH}$ on the postoperative complications and prognosis of $\mathrm{PD}$.

Laparoscopic pancreaticoduodenectomy (LPD) is a technology that has gradually matured in recent years. Compared with open pancreaticoduodenectomy (OPD), it has the advantages of less blood loss and faster postoperative recovery $(9,10)$. However, no reports have addressed the effects of these two surgical methods on intraoperative $\mathrm{pH}$. The present study was performed to evaluate the effects of intraoperative $\mathrm{pH}$ on the postoperative complications and short-term prognosis of patients with periampullary carcinoma undergoing $\mathrm{PD}$ and to compare the intraoperative $\mathrm{pH}$ between LPD and OPD.

\section{MATERIALS AND METHODS}

\section{Study Population and Patient Selection}

This retrospective study collected 635 periampullary carcinoma patients receiving PD treatment between June 2012 and January 2018, including demographic data, surgical variables, postoperative outcomes, pathological results, and extended follow-up. Twenty-three patients with inadequate baseline data or missing primary outcome data were excluded. A total of 612 patients were included in this study. Data were collected on patient characteristics, surgical details, morbidity and mortality, postoperative hospital stay, and pathological outcomes. Percutaneous transhepatic cholangial drainage (PTCD) were performed for all patients with elevated bilirubin preoperatively, and surgical treatment was performed after the bilirubin returned to normal. Preoperative examination included appropriate imaging diagnosis to exclude distant metastases. Preoperative characteristics included age, sex, complications, body mass index (BMI), and American society of anesthesiologists (ASA) score. Surgical details include operative time (from incision to wound closure), estimated blood loss, and transfusion volume (obtained from anesthesia records). Postoperative follow-up was conducted for 3 months (90 days), and all complications were recorded according to the ClavienDindo (CD) system score. Because no objective criteria to recommend laparoscope or open $\mathrm{PD}$ in periampullary carcinoma, the surgical method depended on preoperative evaluation and patient's choice of will. Vascular involvement or prior surgical history or diaphanous variation were taken into account, but were not absolute contraindications to LPD. All patients were informed of the need for surgery and possible complications, as well as the pros and cons of laparoscopic versus open surgery. All patients receiving OPD surgery were performed by 5 experienced doctors in the center, and LPD was performed by Dr. Qin alone. All patients were followed up according to tumor grade to monitor tumor recurrence. The patients were regularly followed up one month after the operation, and then every three months for two years. Followup was conducted every six months thereafter. The follow-up of these included patients ended in December 2019. Overall survival (OS) is defined as the time interval between the date of surgery and the date of death.

\section{Individualized Surgical Strategy}

All OPD surgery were performed by 5 experienced surgeons and LPD was mainly performed by one experienced surgeon (Dr. Qin, director of department of Biliary-Pancreatic Surgery). OPD is performed in the supine position following standard Whipple procedures. With regard to LPD, our center for the first time proposed an "individualized surgical strategy" for LPD. Conventional "five-hole method" can meet the needs of surgical operation. Different from the viewpoint of the first assistant and the dominant surgeon advocated by many centers, our center adopts the fixed strategy of the dominant surgeon, which reduces the change of surgical staff by constantly adjusting body position to cooperate with the exposure of surgical field.

According to whether the tumor invaded or compressed the peripheral vascular system and the degree of invasion, we divided the tumors around the head of the pancreas into five types (11), and conducted specific individualized surgical strategies for each type of pancreatic cancer based on surgical experience and other literature. The most commonly used preferred route of the common retroperitoneal artery in our center had been described in detail in previous articles (12). The advantages of this approach are as follows: firstly, the resectability of the tumor was defined; Secondly, through the retroperitoneal route, the root of all the blood supply arteries on the head of the pancreas was preferentially severed, which reduced the amount of blood loss, prevented massive intraoperative bleeding and ensured safety. In addition, the $\mathrm{R} 0$ resection rate of carcinoma of the head of the pancreas was increased, and the vascular resection length was reduced. The reconstruction of digestive tract was Child type. For pancreas-intestinal anastomosis, the center uses our own original "implantable anastomosis" which had been described in detail in previous articles (13).

\section{Definitions}

PH was measured by arterial blood drawn by the anesthesiologist after specimen removal was completed during the operation. Operative time was the time from the skin incision or trocar to the complete skin closure. Intraoperative estimated blood loss was recorded the anesthesiologist through a vacuum system. Postoperative hospital stay was defined as the days from surgery to discharge. Morbidity and mortality were defined as any complications or deaths that occurred during hospitalization or within 30 days of discharge after surgery. Readmission within 30 days after surgery was considered unplanned. OS was defined as the time interval between the date of surgery and the date of death. Deaths during hospitalization were excluded in the 
calculation of postoperative hospital stay. Postoperative complications were evaluated according to the CD classification system (14) and including postoperative pancreatic fistula (15), delayed gastric emptying (16), bile leakage (17), postoperative bleeding (18).

\section{Statistical Analysis}

Continuous variables are reported as mean with standard deviation or median with interquartile range, and categorical data are presented as frequency. Comparisons between two groups were conducted using Student's t-test or the MannWhitney test for quantitative data and the chi-square test or Fisher's exact test for qualitative data. Survival analysis was performed by the Kaplan-Meier method, and the log-rank test was used to compare the different survival curves. The cut-off values of $\mathrm{pH}$ for predicting 18-month survival were determined using a receiver operating characteristic (ROC) curve, and the $\mathrm{pH}$ was then dichotomized into low and high groups. Univariate Cox regression analysis was conducted to estimate the risk factors for OS, and variables with a $P$ value of $<0.1$ were then entered into the multivariate Cox regression model. The hazard ratio and $95 \%$ confidence interval were calculated, and the lower limit of the $95 \%$ confidence interval above zero was considered a significant risk factor. All statistical analyses were performed using SAS statistical software (SAS Institute, Inc., Cary, NC, USA), and two-sided hypothesis testing with a predetermined level of $P<0.05$ was considered statistically significant.

\section{RESULTS}

\section{Patient Characteristics and ROC Analysis}

From June 2012 to January 2018, 612 patients with periampullary adenocarcinoma underwent $\mathrm{PD}$ in our center. The last follow-up was on 15 December 2019, and the median follow-up period was 18 months (IQR, 6-42). The $\mathrm{pH}$ was recorded before suturing peritoneum, and the median $\mathrm{pH}$ was 7.37 (range, 6.69-7.64). As shown in Figure 1, the patients were divided into a high and low $\mathrm{pH}$ group according to the cut-off value of the ROC curve (7.34) (a sensitivity of $80.8 \%$ and a specificity of $92.2 \%$ ). The area under the curve (AUC) of $\mathrm{pH}$ was 0.923 (95\% CI, 0.897-0.952, $\mathrm{P}<0.001)$. The low $\mathrm{pH}$ group $(\mathrm{pH} \leq$ $7.34)$ comprised 421 patients, and the high $\mathrm{pH}$ group $(\mathrm{pH}>7.34)$ comprised 191 patients.

\section{Correlations Between pH and Patient Characteristics}

The relationships between the $\mathrm{pH}$ and the patients' clinical parameters are shown in Table 1. There was no significant correlation between $\mathrm{pH}$ and age, BMI, sex, blood group, diabetes mellitus, family history, tumor size, alkaline phosphatase, gamma-glutamyl transpeptidase, cholesterol, triglyceride, lactate dehydrogenase, total protein, albumin, white blood cells, preoperative total bilirubin, preoperative biliary drainage, ASA, TNM stage, histopathological diagnosis, or serum tumor markers.

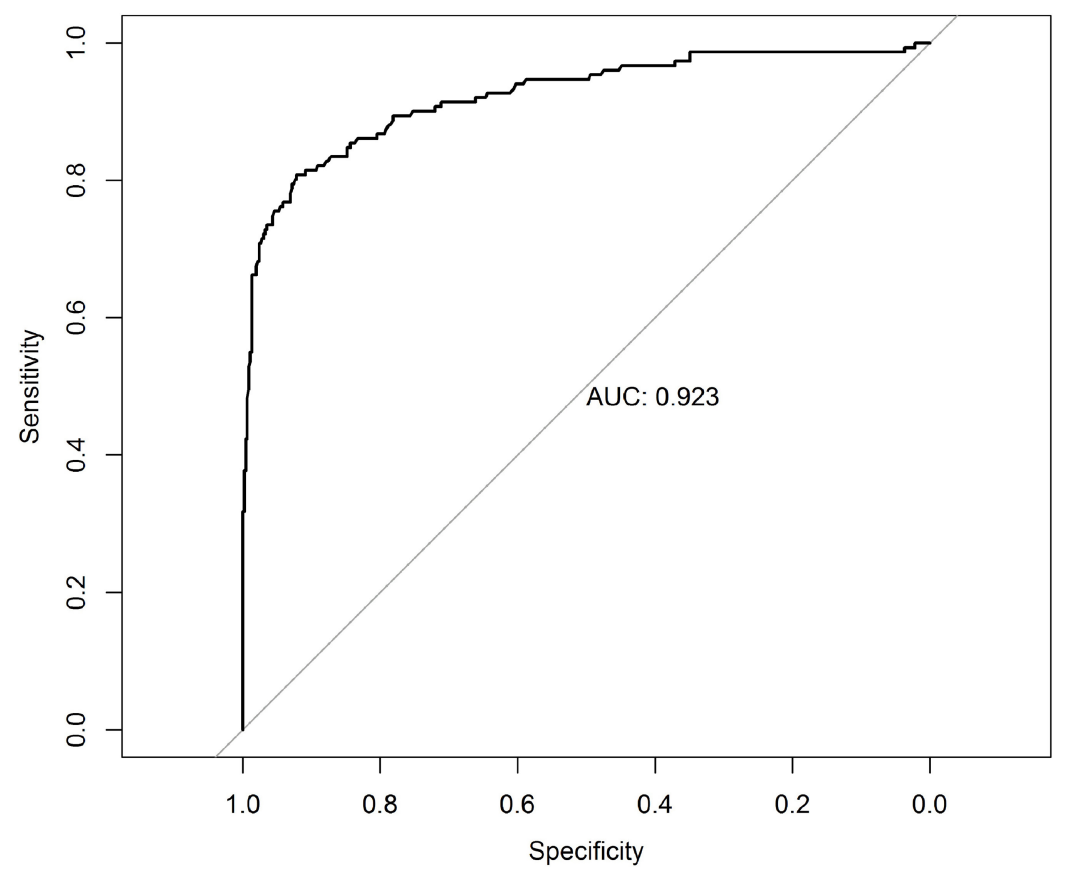

FIGURE 1 | The receiver operating characteristic curve grouped by pH for survival at 18 months after pancreaticoduodenectomy. AUC, area under the curve. 
TABLE 1 | Baseline characteristics of the patients in Low-pH and High-pH group.

\begin{tabular}{|c|c|c|c|}
\hline Variable & $\begin{array}{c}\text { Low-pH } \\
\text { (421) }\end{array}$ & $\begin{array}{l}\text { High-pH } \\
\text { (191) }\end{array}$ & $P$ value \\
\hline Age, Mean (SD), year & $55.89(9.94)$ & $54.20(11.70)$ & 0.066 \\
\hline Sex, $N(\%)$ & & & 0.128 \\
\hline Males & $268(63.66)$ & $115(60.21)$ & \\
\hline Females & $153(36.34)$ & $76(39.80)$ & \\
\hline Blood group, N (\%) & & & 0.323 \\
\hline $\mathrm{B}$ & $103(24.47)$ & $54(28.42)$ & \\
\hline$A B$ & $30(7.13)$ & 17 (8.95) & \\
\hline 0 & $138(32.78)$ & $65(34.21)$ & \\
\hline Diabetes mellitus, $\mathrm{N}(\%)$ & & & 0.320 \\
\hline No & 395 (94.27) & $176(92.15)$ & \\
\hline Yes & $24(5.73)$ & $15(7.85)$ & \\
\hline r-GT, Mean (SD), U/L & 419.39 (459.69) & $393.98(481.88)$ & 0.535 \\
\hline Cholesterol, Mean (SD), mmol/L & $5.02(2.01)$ & $4.74(1.76)$ & 0.100 \\
\hline Triglyceride, Mean (SD), mmol/L & $1.93(1.64)$ & $1.75(1.33)$ & 0.301 \\
\hline $\mathrm{LDH}$, Mean (SD), U/L & $188.55(57.78)$ & $191.59(62.64)$ & 0.640 \\
\hline Total protein, Mean (SD), g/L & $67.02(8.17)$ & $67.00(6.25)$ & 0.975 \\
\hline Albumin, Mean (SD), g/L & $37.86(5.04)$ & $38.41(4.27)$ & 0.199 \\
\hline White Blood Cell, Mean (SD), $10^{9} / \mathrm{L}$ & $6.17(2.43)$ & $5.97(4.85)$ & 0.487 \\
\hline Preoperative total bilirubin, Mean (SD), $\mu$ mol & $69.95(39.61)$ & $64.71(37.77)$ & 0.375 \\
\hline Preoperative biliary drainage, $\mathrm{N}(\%)$ & & & 0.682 \\
\hline No & 275 (65.32) & $128(67.02)$ & \\
\hline Yes & $146(34.68)$ & $63(32.98)$ & \\
\hline ASA, N (\%) & & & 0.088 \\
\hline N1 & $107(25.31)$ & $48(25.13)$ & \\
\hline N2 & $18(4.32)$ & $14(7.33)$ & \\
\hline Distance metastasis, N (\%) & & & 0.921 \\
\hline MO & $421(100)$ & $191(100)$ & \\
\hline M1 & $0(0)$ & $0(0)$ & \\
\hline pStage, N (\%) & & & 0.294 \\
\hline $\mathrm{IA}$ & $136(32.30)$ & $63(32.98)$ & \\
\hline $\mathrm{IB}$ & $118(28.03)$ & $58(30.37)$ & \\
\hline$\| A$ & 38 (9.03) & $6(3.14)$ & \\
\hline$\| \mathrm{B}$ & $107(25.42)$ & $48(25.13)$ & \\
\hline III & $22(5.23)$ & $16(8.38)$ & \\
\hline IV & $0(0)$ & $0(0)$ & \\
\hline Histopathological diagnosis, N (\%) & & & 0.357 \\
\hline Bile duct carcinoma & $38(9.03)$ & $16(8.38)$ & \\
\hline Ampullary carcinoma & $41(9.74)$ & $19(9.95)$ & \\
\hline Pancreatic carcinoma & $180(42.76)$ & $83(43.46)$ & \\
\hline Duodenal carcinoma & $162(38.48)$ & $73(38.22)$ & \\
\hline CA19-9, Mean (SD), u/ml & 490.34 (1523.39) & $309.16(1196.47)$ & 0.155 \\
\hline CA125, Mean (SD), u/ml & $23.55(30.31)$ & $22.89(35.64)$ & 0.851 \\
\hline CEA, Mean (SD), ng/ml & $6.56(40.82)$ & $4.11(9.76)$ & 0.422 \\
\hline
\end{tabular}

BMI, body mass index; ALP, alkaline phosphatase; $r$-GT, gamma-glutamyl transpeptidase; LDH, lactate dehydrogenase; ASA, American society of anesthesiologists; CA19-9, carcinoembryonic antigen 19-9; CA125, carcinoembryonic antigen 125; CEA, carcinoembryonic antigen; SD, standard derivation; IQR, interquartile range. 


\section{Correlations Between pH and Intraoperative Characteristics}

As shown in Table 2, low $\mathrm{pH}$ was associated with a longer operative time (median, 363 vs 307 min; $P<0.001$ ), a higher intraoperative bleeding volume (mean, 445 vs $259 \mathrm{ml} ; P<0.001$ ), and a higher intraoperative blood transfusion volume (mean, 1.62 vs $0.98 \mathrm{U} ; P=0.015$ ). There was no significant difference in the R0 removal rate between the low and high $\mathrm{pH}$ groups (median, $84.56 \%$ vs $87.43 \% ; P=0.350$ ). Similarly, there was no significant difference in the number of lymph nodes cleared between the low and high $\mathrm{pH}$ groups $(P=0.476)$. There was a significant difference in the operation method between the low and high $\mathrm{pH}$ groups $(P<0.001)$.

\section{Correlations Between pH and Postoperative Characteristics}

The patients' postoperative factors are shown in Table 3. The rate of total complications was significantly higher in the low $\mathrm{pH}$ group than high $\mathrm{pH}$ group $(31.83 \%$ vs $18.32 \%, P=0.026)$. Specifically, postoperative pancreatic fistula $(19.95 \%$ vs $10.99 \%$, $P=0.031)$, renal failure $(2.14 \%$ vs $0.00 \%, P=0.016)$, infection
(5.24\% vs $1.05 \%, P=0.021$ ), and delayed gastric emptying (26.37\% vs $17.28 \%, P=0.024)$ were more common in the low $\mathrm{pH}$ group. There was no significant difference in the rate of positive lymph nodes sent for examination between the low and high $\mathrm{pH}$ groups $(P=0.385)$. There was also no difference in the 30 -day unplanned readmission rate after surgery (4.75\% vs $4.71 \%$, $P=0.163$ ); however, the low $\mathrm{pH}$ group had a longer postoperative hospital stay ( 23 vs 19 days, $P=0.043$ ). The reoperation rate was similar between the low and high $\mathrm{pH}$ groups $(2.14 \%$ vs $0.52 \%, P=$ $0.144)$. The 90 -day mortality rate was significantly higher in the low than high $\mathrm{pH}$ group $(4.99 \%$ vs $0.52 \%, P<0.001)$.

\section{pH Is an Independent Prognostic Marker for Patients Undergoing PD}

As shown in Table 4, we performed univariate and multivariate survival analyses for OS to determine whether $\mathrm{pH}$ was an independent prognostic factor for periampullary carcinoma. Single-factor analysis showed that $\mathrm{pH}$, operation method, ASA, tumor stage, $\mathrm{R}$ state, and pancreas texture were significantly correlated with OS $(P<0.001)$. To determine the independent prognostic factors, the important factors in the univariate

TABLE 2 | Comparison of intraoperative factors between Low-pH and High-pH group.

\begin{tabular}{|c|c|c|c|}
\hline Variable & $\begin{array}{c}\text { Low-pH } \\
\text { (421) }\end{array}$ & $\begin{array}{c}\text { High-pH } \\
\text { (191) }\end{array}$ & $P$ value \\
\hline Duration of surgery, Mean (SD), min & $362.98(111.20)$ & $307.43(86.81)$ & $<0.001$ \\
\hline Intraoperative bleeding, Mean (SD), ml & $444.52(476.63)$ & $259.38(327.14)$ & $<0.001$ \\
\hline Red blood cell transfusion, Mean (SD), U & $1.62(2.44)$ & $0.98(3.94)$ & 0.015 \\
\hline Operation method, N (\%) & & & $<0.001$ \\
\hline OPD & $308(73.16)$ & $54(28.27)$ & \\
\hline LPD & $113(26.84)$ & $137(71.73)$ & \\
\hline R state, N (\%) & & & 0.350 \\
\hline RO & $356(84.56)$ & $167(87.43)$ & \\
\hline R1 & $65(15.44)$ & $24(12.57)$ & \\
\hline Lymph node dissection, Median (IQR) & 15 (13 25) & $16(13 \sim 28)$ & 0.476 \\
\hline
\end{tabular}

$L P D$, laparoscopic pancreaticoduodenectomy; OPD, open pancreaticoduodenectomy; SD, standard derivation; IQR, interquartile range.

TABLE 3 | Comparison of short-term postoperative results between Low-pH and High-pH group.

\begin{tabular}{|c|c|c|c|}
\hline Variable & $\begin{array}{c}\text { Low-pH } \\
\text { (421) }\end{array}$ & $\begin{array}{c}\text { High-pH } \\
\text { (191) }\end{array}$ & P value \\
\hline Postoperative hospital stay, Mean (SD), day & $22.94(9.73)$ & $19.14(10.11)$ & 0.043 \\
\hline Positive lymph node, Median (IQR) & $0.82(2.34)$ & $0.66(1.59)$ & 0.385 \\
\hline Aggregate complications, N (\%) & $134(31.83)$ & $35(18.32)$ & 0.026 \\
\hline Renal failure & $9(2.14)$ & $0(0.00)$ & 0.016 \\
\hline Pulmonary complications & $4(0.95)$ & $1(0.52)$ & 0.449 \\
\hline Hepatic failure & $2(0.48)$ & $0(0.00)$ & 0.340 \\
\hline Gastrointestinal fistula & $0(0.00)$ & $0(0.00)$ & 0.602 \\
\hline Biliary leakage & $2(0.48)$ & $3(1.57)$ & 0.164 \\
\hline Postpancreatectomy hemorrhage & $33(7.86)$ & $16(8.38)$ & 0.827 \\
\hline Pancreatic fistula & 84 (19.95) & $21(10.99)$ & 0.031 \\
\hline Delayed gastric emptying of grade $\mathrm{B} / \mathrm{C}$ & $111(26.37)$ & $33(17.28)$ & 0.024 \\
\hline Infection & $22(5.24)$ & $2(1.05)$ & 0.021 \\
\hline Reoperation N (\%) & $9(2.14)$ & $1(0.52)$ & 0.144 \\
\hline 30 days unplanned readmission, $\mathrm{N}(\%)$ & $20(4.75)$ & $9(4.71)$ & 0.983 \\
\hline 90-Day mortality, N (\%) & 21 (4.99) & $1(0.52)$ & 0.006 \\
\hline
\end{tabular}

$S D$, standard derivation; $I Q R$, interquartile range. 
TABLE 4 | Risk factors analysis of $\mathrm{pH}$ as a prognostic factor for periampullary carcinoma.

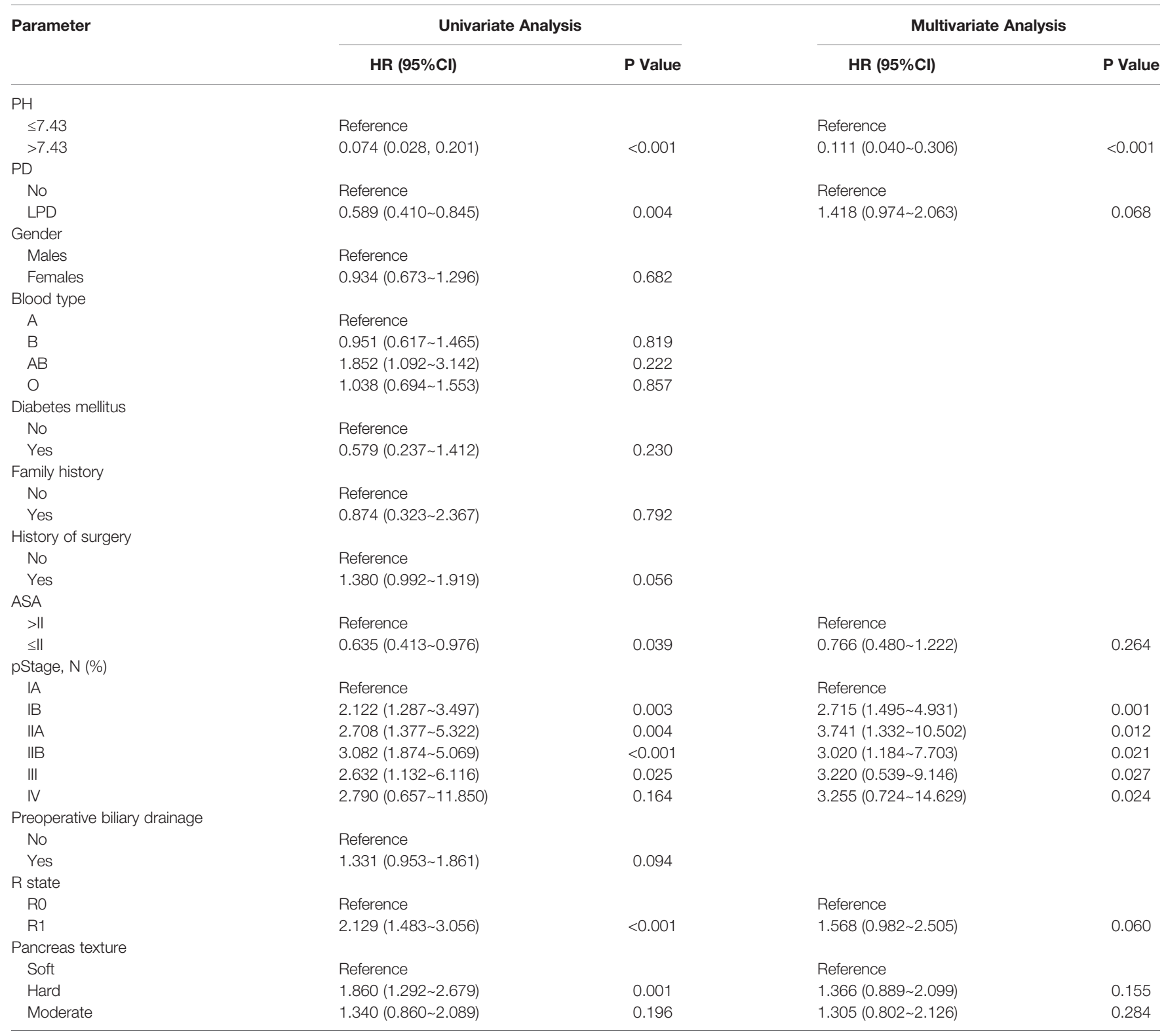

ASA, American society of anesthesiologists; $S D$, standard derivation; IQR, interquartile range.

analysis were included in the multivariate analysis. The multivariate analysis showed that $\mathrm{pH}, \mathrm{R}$ state and tumor stage were independent prognostic factors for OS $(P<0.001)$. Besides, the Kaplan-Meier survival curve suggested that low-pH was associated with low OS, and the difference in survival rate between the low-pH group and the high-pH group was statistically significant $(P<0.001$, Figure 2$)$.

\section{Differences in Effect of LPD and OPD on $\mathrm{pH}$}

As shown in Table 5, the average $\mathrm{pH}$ in the LPD group was 7.41, which was significantly higher than that in the OPD group (7.34) $(P<0.001)$. The operation time was significantly shorter in the LPD than OPD group (305 vs $374 \mathrm{~min}, P<0.001$ ), as was the blood loss volume (205 vs $512 \mathrm{ml}, P<0.001)$. The intraoperative red blood cell infusion volume was also significantly lower in the LPD than OPD group ( 0.42 vs $2.12 \mathrm{U}, P<0.001)$. The postoperative hospital stay was significantly shorter in the LPD than OPD group (20 vs 21 days, $P=0.005$ ). There were no statistically significant differences in postoperative complications, 90-day mortality, 30-day unplanned hospitalization, or the R0 resection rate between the two groups.

\section{DISCUSSION}

The annual incidence of periampullary adenocarcinoma has been steadily increasing. The only effective treatment for 


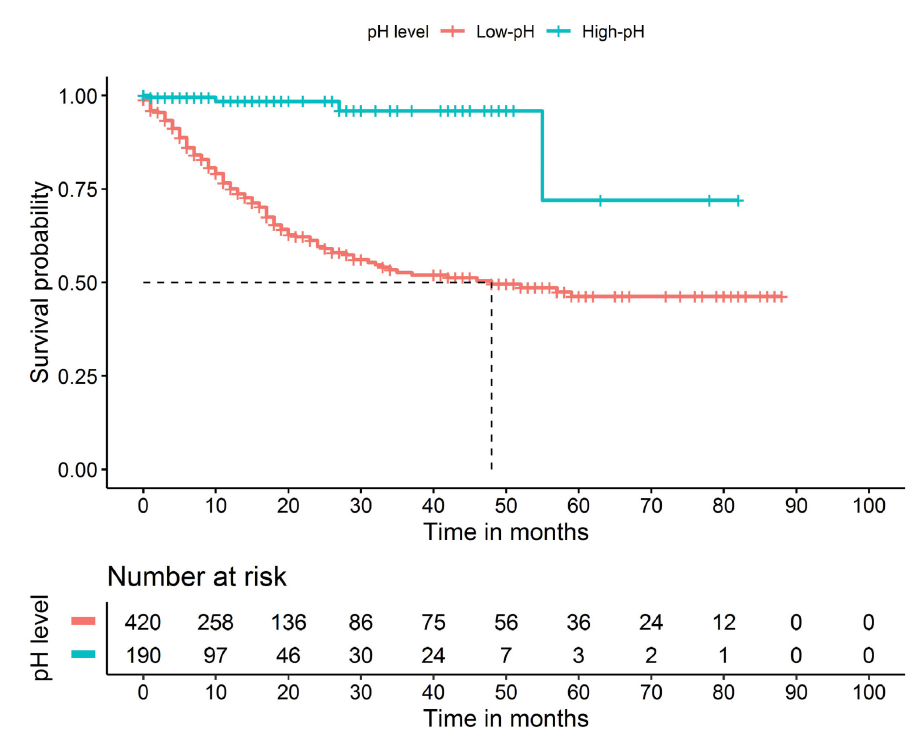

FIGURE 2 | Kaplan-Meier curves for overall survival of patients who received pancreaticoduodenectomy based on $\mathrm{pH}(\mathrm{P}<0.001)$.

TABLE 5 | Comparison characteristics between laparoscopic pancreaticoduodenectomy (LPD) and open pancreaticoduodenectomy (OPD).

\begin{tabular}{|c|c|c|c|}
\hline Parameter & OPD & LPD & $P$ value \\
\hline Age, Mean (SD), year & $54.94(10.42)$ & $55.97(10.71)$ & 0.234 \\
\hline Sex (Males), $N(\%)$ & 215 (59.39) & $145(58.00)$ & 0.731 \\
\hline Diabetes mellitus (Yes), N (\%) & $25(6.94)$ & $14(5.60)$ & 0.504 \\
\hline Family history (Yes), N (\%) & $9(2.49)$ & $1(0.40)$ & 0.045 \\
\hline History of surgery (Yes), N (\%) & $130(36.01)$ & $78(31.20)$ & 0.217 \\
\hline CEA, Median Mean (SD), ng/ml & $6.83(43.68)$ & $4.30(10.84)$ & 0.381 \\
\hline Preoperative total bilirubin Median Mean (SD), $\mu$ mol & $72.50(43.49)$ & $63.60(32.77)$ & 0.101 \\
\hline Duration of surgery, median Mean (SD), min & $374.01(109.50)$ & $304.62(89.39)$ & $<0.001$ \\
\hline Intraoperative bleeding, median Mean (SD), ml & $512.32(516.50)$ & $204.89(200.13)$ & $<0.001$ \\
\hline ASA, N (\%) & & & 0.096 \\
\hline$>\|$ & $51(14.09)$ & $24(9.60)$ & \\
\hline$\| A$ & $27(7.46)$ & $17(6.80)$ & \\
\hline$\| B$ & $98(27.07)$ & $57(22.80)$ & \\
\hline III & $22(6.08)$ & $16(6.40)$ & \\
\hline IV & $0(0)$ & $0(0)$ & \\
\hline R state, $N(\%)$ & & & 0.138 \\
\hline RO & $303(83.70)$ & $220(88.00)$ & \\
\hline $\mathrm{R} 1$ & $59(16.30)$ & $30(12.00)$ & \\
\hline Red blood cell transfusion, Mean (SD), $U$ & $2.12(3.63)$ & $0.42(1.16)$ & $<0.001$ \\
\hline Lymph node dissection, median (IQR) & $7.31(6.42)$ & $6.68(6.21)$ & 0.236 \\
\hline Positive lymph node, Median (IQR) & $0.84(2.42)$ & $0.67(1.62)$ & 0.340 \\
\hline Postoperative hospital stay, median (IQR), day & $21(17 \sim 28)$ & 20 (16 25) & 0.005 \\
\hline 30 days unplanned readmission, $\mathrm{N}(\%)$ & $14(3.87)$ & $15(6.00)$ & 0.222 \\
\hline Aggregate complications (Yes), N (\%) & $102(28.18)$ & $67(26.80)$ & 0.708 \\
\hline
\end{tabular}

BMI, body mass index; CA19-9, carcinoembryonic antigen 19-9; CA125, carcinoembryonic antigen 125; CEA, carcinoembryonic antigen; SD, standard derivation; IQR, interquartile range. 
periampullary adenocarcinoma is $\mathrm{PD}$, but the cure rate is only $20 \%$ (19). PD is a complicated operation, and its numerous postoperative complications and low survival rate are of concern among surgeons (20-22). Therefore, many institutions have studied the factors affecting the postoperative prognosis of patients undergoing $\mathrm{PD}$. Because of the long operation time and high degree of difficulty of $\mathrm{PD}$, clinical adverse events such as hypotension, excessive blood loss, and hypothermia can lead to postoperative acidosis. In the present study, we investigated the relationship of intraoperative $\mathrm{pH}$ with postoperative complications and survival. To our knowledge, this is the first study to investigate the effect of intraoperative $\mathrm{pH}$ on the prognosis underwent $\mathrm{PD}$.

Using ROC curve analysis, the patients were divided into a high and low $\mathrm{pH}$ group according to the cut-off value of 7.34 for 18-month survival. The results showed that intraoperative $\mathrm{pH}$ was not influenced by preoperative factors. However, an analysis of intraoperative factors showed that the low $\mathrm{pH}$ group contained more patients who lost a larger amount of blood during surgery or had a longer operation time. This result is consistent with the view that the intraoperative $\mathrm{pH}$ changes in accordance with a prolonged operation time and increased intraoperative blood loss (8). For patients undergoing PD, both OPD and LPD are used as routine operations in our center. Our statistical analysis also showed that the high $\mathrm{pH}$ group contained a greater proportion of patients undergoing LPD than OPD. Our analysis of the patients' postoperative characteristics showed that a lower $\mathrm{pH}$ was associated with a higher incidence of postoperative total complications. In particular, the incidence of pancreatic leakage was higher in the low $\mathrm{pH}$ group; the patients in this group also had longer hospital stays and higher 90-day mortality. These findings indicate that a low intraoperative $\mathrm{pH}$ is associated with a poor short-term prognosis. Therefore, when the $\mathrm{pH}$ of patients with periampullary cancer is $<7.34$ during surgical procedures, appropriate measures should be taken as soon as possible to increase the $\mathrm{pH}$. The prognosis after $\mathrm{pH}$ improvement is not discussed in this paper; therefore, the efficacy of $\mathrm{pH}$ improvement remains to be further studied.

In the present study, we also evaluated the risk factors for postoperative survival of patients with periampullary carcinoma underwent $\mathrm{PD}$ and found that intraoperative $\mathrm{pH}$ was an important factor affecting the prognosis. Kaplan-Meier analysis clearly showed significant differences in survival of patients with periampullary carcinoma between the low and high $\mathrm{pH}$ groups. Because of the short follow-up time, the effect of $\mathrm{pH}$ on the long-term prognosis needs to be further verified. The mechanism by which intraoperative $\mathrm{pH}$ can affect the prognosis of periampullary carcinoma is still unclear. Indeed, whether acidosis is a marker of postoperative complications or the cause of postoperative complications remains unknown (23). Although there are many causes of acidosis, such as a large intraoperative blood loss volume, long operation time, hypothermia, improper surgical technique, and others, many of these factors can be avoided, and this is the focus of our attention. Because of the difficult operation, long operation time, and large intraoperative blood loss associated with PD, perioperative management is particularly important to avoid low intraoperative $\mathrm{pH}$. On this basis, it is especially important to treat low $\mathrm{pH}$ early in the perioperative period because it may help to avoid complications such as infection or kidney damage, which almost certainly lead to death. Evidence suggests that acidosis may interfere with hemodynamics (24) and innate immunity (25), which may help to explain the high complication and short-term mortality rates associated with a low $\mathrm{pH}$ in this study; however, the exact mechanism remains unclear and needs further exploration. Although different types of acidosis may have different effects on the prognosis (26), we did not further classify acidosis. However, intraoperative $\mathrm{pH}$ can be an early indicator of a higher risk of postoperative complications and short-term death in patients with periampullary carcinoma, enabling early initiation of treatment.

In recent years, LPD has attracted increasingly more attention. Since 2014, LPD has been widely carried out in our center as a routine surgical method. However, the advantages and disadvantages of LPD and OPD are still controversial. The $\mathrm{pH}$ can reflect intraoperative blood loss, body temperature, and other comprehensive conditions; thus, we also wanted to compare the difference in $\mathrm{pH}$ between LPD and OPD. We found that the intraoperative $\mathrm{pH}$ was significantly higher in the LPD than OPD group, which was closer to the $\mathrm{pH}$ value obtained through ROC curve analysis. The reason may be that the operation time was slightly shorter and the intraoperative blood loss was significantly lower for LPD than OPD, which is consistent with the $\mathrm{pH}$ reflecting intraoperative blood loss. Compared with OPD, the shorter operative time of LPD is slightly different from that reported by other centers (27); this may be due to the fact that LPD requires a smaller incision and a shorter time to close the abdominal cavity. Furthermore, the laparoscopic pancreaticoduodenectomy technique developed by Professor Qin (13) at our center shortened the operating time. The postoperative hospitalization duration was also shorter in the LPD than OPD group. Thus, patients with a more alkaline $\mathrm{pH}$ in the LPD group recovered more quickly and were more likely to leave the hospital sooner, thus entering the next treatment stage.

Our study has many important clinical implications. In particular, this new and innovative study is the first to clearly indicate that a weakly alkaline intraoperative $\mathrm{pH}$ affects the prognosis of patients with periampullary carcinoma undergoing PD. However, our study also has some limitations. Because of the observational design and retrospective nature of the study, we were unable to establish a causal relationship between acidosis and prognosis. Additionally, previous studies have shown that different types of acidosis have different clinical consequences, and our study focused only on the $\mathrm{pH}$ and did not classify acidosis. 


\section{CONCLUSIONS}

In summary, the results of this study indicate that the intraoperative $\mathrm{pH}$ has a good predictive effect on the postoperative complications and short-term prognosis of patients with periampullary carcinoma undergoing PD. Our risk factor analysis showed that $\mathrm{pH}$ can be used as a prognostic factor for periampullary carcinoma. In addition, the faster postoperative recovery after LPD than OPD may be related to less $\mathrm{pH}$ reduction during the operation. Considering that this was only a single-center study, a larger number of well-designed prospective studies should be conducted to further confirm this conclusion.

\section{REFERENCES}

1. Siegel RL, Miller KD, Jemal A. Cancer Statistics, 2016. CA Cancer J Clin (2016) 66:7-30. doi: 10.3322/caac.21332

2. Kimura W, Miyata H, Gotoh M, Hirai I, Kenjo A, Kitagawa $\mathrm{Y}$, et al. A Pancreaticoduodenectomy Risk Model Derived From 8575 Cases From a National Single-Race Population (Japanese) Using a Web-Based Data Entry System: The 30-Day and in-Hospital Mortality Rates for Pancreaticoduodenectomy. Ann Surg (2014) 259:773-80. doi: 10.1097/SLA.0000000000000263

3. Gebauer F, Kloth K, Tachezy M, Vashist YK, Cataldegirmen G, Izbicki JR, et al. Options and Limitations in Applying the Fistula Classification by the International Study Group for Pancreatic Fistula. Ann Surg (2012) 256:130-8. doi: 10.1097/SLA.0b013e31824f24e4

4. Grobmyer SR, Rivadeneira DE, Goodman CA, Mackrell P, Lieberman MD, Daly JM. Pancreatic Anastomotic Failure After Pancreaticoduodenectomy. Am J Surg (2000) 180:117-20. doi: 10.1016/s0002-9610(00)00423-2

5. Tsuji M, Kimura H, Konishi K, Yabushita K, Maeda K, Kuroda Y. Management of Continuous Anastomosis of Pancreatic Duct and Jejunal Mucosa After Pancreaticoduodenectomy: Historical Study of 300 Patients. Surgery (1998) 123:617-21. doi: 10.1016/S0039-6060(98)70199-0

6. Moore EE, Thomas G. Orr Memorial Lecture. Staged Laparotomy for the Hypothermia, Acidosis, and Coagulopathy Syndrome. Am J Surg (1996) 172:405-10. doi: 10.1016/S0002-9610(96)00216-4

7. Morgan K, Mansker D, Adams DB. Not Just for Trauma Patients: Damage Control Laparotomy in Pancreatic Surgery. J Gastrointest Surg (2010) 14:76872. doi: 10.1007/s11605-010-1186-y

8. Waters JH, Miller LR, Clack S, Kim JV. Cause of Metabolic Acidosis in Prolonged Surgery. Crit Care Med (1999) 27:2142-6. doi: 10.1097/00003246199910000-00011

9. Croome KP, Farnell MB, Que FG, Reid-Lombardo KM, Truty MJ, Nagorney DM, et al. Total Laparoscopic Pancreaticoduodenectomy for Pancreatic Ductal Adenocarcinoma: Oncologic Advantages Over Open Approaches? Ann Surg (2014) 260:633-8. doi: 10.1097/SLA.0000000000000937

10. Asbun HJ, Stauffer JA. Laparoscopic vs Open Pancreaticoduodenectomy: Overall Outcomes and Severity of Complications Using the Accordion Severity Grading System. J Am Coll Surg (2012) 215:810-9. doi: 10.1016/ j.jamcollsurg.2012.08.006

11. Wang M, Zhu F, Qin R, Peng S. Which Is the Best Surgical Approach for the Pancreatic Cancer? A Classification of Pancreatic Cancer to Guide Operative Decisions Is Needed. Ann Surg (2017) 265:E81-2. doi: 10.1097/ SLA.0000000000001271

12. Wang $M$, Zhang $H$, Zhu F, Peng F, Wang $X$, Shen $M$, et al. Pancreaticoduodenectomy for Borderline Resectable Pancreatic Head Cancer With a Modified Artery-First Approach Technique. Hepatobiliary Pancreat Dis Int (2017) 16:215-1. doi: 10.1016/s1499-3872(16)60171-6

13. Wang $M, X u S$, Zhang $H$, Peng $S$, Zhu F, Qin R. Imbedding Pancreaticojejunostomy Used in Pure Laparoscopic Pancreaticoduodenectomy for Nondilated Pancreatic Duct. Surg Endosc (2017) 31:1986-92. doi: 10.1007/ s00464-016-4805-1

\section{DATA AVAILABILITY STATEMENT}

The original contributions presented in the study are included in the article/supplementary material. Further inquiries can be directed to the corresponding authors.

\section{AUTHOR CONTRIBUTIONS}

CD: Conceptualization, methodology, formal analysis, investigation, and writing - original draft. MW: Funding acquisition and supervision. TW: Formal analysis. RQ: Funding acquisition and supervision. All authors contributed to the article and approved the submitted version.

14. Baker MS, Sherman KL, Stocker SJ, Hayman AV, Bentrem DJ, Prinz RA, et al. Using a Modification of the Clavien-Dindo System Accounting for Readmissions and Multiple Interventions: Defining Quality for Pancreaticoduodenectomy. J Surg Oncol (2014) 110:400-6. doi: 10.1002/ jso. 23663

15. Bassi C, Marchegiani G, Dervenis C, Sarr M, Abu Hilal M, Adham M, et al. The 2016 Update of the International Study Group (ISGPS) Definition and Grading of Postoperative Pancreatic Fistula: 11 Years After. Surgery (2017) 161:584-91. doi: 10.1016/j.surg.2016.11.014

16. Wente MN, Bassi C, Dervenis C, Fingerhut A, Gouma DJ, Izbicki JR, et al. Delayed Gastric Emptying (DGE) After Pancreatic Surgery: A Suggested Definition by the International Study Group of Pancreatic Surgery (ISGPS). Surgery (2007) 142:761-8. doi: 10.1016/j.surg.2007.05.005

17. Koch M, Garden OJ, Padbury R, Rahbari NN, Adam R, Capussotti L, et al. Bile Leakage After Hepatobiliary and Pancreatic Surgery: A Definition and Grading of Severity by the International Study Group of Liver Surgery. Surgery (2011) 149:680-8. doi: 10.1016/j.surg.2010.12.002

18. Wente MN, Veit JA, Bassi C, Dervenis C, Fingerhut A, Gouma DJ, et al. Postpancreatectomy Hemorrhage (PPH): An International Study Group of Pancreatic Surgery (ISGPS) Definition. Surgery (2007) 142:20-5. doi: 10.1016/ j.surg.2007.02.001

19. Kamisawa T, Wood LD, Itoi T, Takaori K. Pancreatic Cancer. Lancet (2016) 388:73-85. doi: 10.1016/S0140-6736(16)00141-0

20. Böttger TC, Junginger T. Factors Influencing Morbidity and Mortality After Pancreaticoduodenectomy: Critical Analysis of 221 Resections. World J Surg (1999) 23:164-71. doi: 10.1007/pl00013170

21. Ho CK, Kleeff J, Friess H, Büchler MW. Complications of Pancreatic Surgery. HPB (2005) 7:99-108. doi: 10.1080/13651820510028936

22. Yeo CJ, Cameron JL, Sohn TA, Lillemoe KD, Pitt HA, Talamini MA, et al. Six Hundred Fifty Consecutive Pancreaticoduodenectomies in the 1990s: Pathology, Complications, and Outcomes. Ann Surg (1997) 226:248-57. doi: 10.1097/00000658-199709000-00004

23. Rocktaeschel J, Morimatsu H, Uchino S, Bellomo R. Unmeasured Anions in Critically Ill Patients: Can They Predict Mortality? Crit Care Med (2003) 31:2131-6. doi: 10.1097/01.CCM.0000079819.27515.8E

24. Kellum JA, Song M, Venkataraman R. Effects of Hyperchloremic Acidosis on Arterial Pressure and Circulating Inflammatory Molecules in Experimental Sepsis. Chest (2004) 125:243-8. doi: 10.1378/chest.125.1.243

25. Kellum JA, Song M, Li J. Science Review: Extracellular Acidosis and the Immune Response: Clinical and Physiologic Implications. Crit Care (2004) 8:331-6. doi: 10.1186/cc2900

26. Kaplan LJ, Kellum JA. Initial Ph, Base Defcit, Lactate, Anion Gap, Strong Ion Difference, and Strong Ion Gap Predict Outcome From Major Vascular Injury. Crit Care Med (2004) 32:1120-4. doi: 10.1097/01.ccm.0000125517. 28517.74

27. Sharpe SM, Talamonti MS, Wang CE, Prinz RA, Roggin KK, Bentrem DJ, et al. Early National Experience With Laparoscopic Pancreaticoduodenectomy for Ductal Adenocarcinoma: A Comparison of Laparoscopic Pancreaticoduodenectomy and Open Pancreaticoduodenectomy From the 
National Cancer Data Base. J Am Coll Surg (2015) 221:175-84. doi: 10.1016/ j.jamcollsurg.2015.04.021

Conflict of Interest: The authors declare that the research was conducted in the absence of any commercial or financial relationships that could be construed as a potential conflict of interest.

Publisher's Note: All claims expressed in this article are solely those of the authors and do not necessarily represent those of their affiliated organizations, or those of the publisher, the editors and the reviewers. Any product that may be evaluated in this article, or claim that may be made by its manufacturer, is not guaranteed or endorsed by the publisher.

Copyright (๑) 2021 Dang, Wang, Wang and Qin. This is an open-access article distributed under the terms of the Creative Commons Attribution License (CC BY). The use, distribution or reproduction in other forums is permitted, provided the original author(s) and the copyright owner(s) are credited and that the original publication in this journal is cited, in accordance with accepted academic practice. No use, distribution or reproduction is permitted which does not comply with these terms. 